\title{
Role of Alleles and Genotypes of Polymorphisms of IL-18 (-607 C/A; and -137 C/G), IFN- $\gamma$ (+874 A/T) and TNF-a (-238 A/G and -308 A/G) and HLA-G Genes in the Susceptibility of Hepatocellular Carcinoma
}

\author{
Andreza Correa Teixeira, \\ Ana de Lourdes Candolo Martinelli and \\ Eduardo Antonio Donadi \\ Additional information is available at the end of the chapter \\ http://dx.doi.org/10.5772/56350
}

\section{Introduction}

Hepatocellular carcinoma (HCC) is a primary malignant tumor of the liver which represents a serious public health problem in the world, corresponding to the fifth more frequent malignant neoplasia among men, the eighth among women, and the third cause of cancer death in the world [1,2]. Seventy to ninety percent of HCC cases occur in patients with cirrhosis or with chronic liver disease, with cell injury followed by regeneration mediated by the immune response playing an important role in hepatocarcinogenesis [3].

In Brazil, a national survey to update HCC epidemiology and clinical profile of patients with HCC (29 centers, with 1,405 patients diagnosed with HCC from 2004 to 2009) showed that the median age at diagnosis was 59 years (1-92 years old; $78 \%$ male) and $98 \%$ of the patients had cirrhosis (1279/1308), with the hepatitis C virus being the main etiology (54\%), followed by hepatitis B virus (16\%) and alcohol (14\%). In Southeastern and Southern Brazil, hepatitis C virus accounted for over $55 \%$ of cases. In the Northeast and North, hepatitis $C$ virus accounted for less than $50 \%$, and hepatitis B virus accounted for $22-25 \%$ of cases [4]. In Ribeirão Preto, Southeastern Brazil, the clinical characteristics of 130 patients with HCC attended at the University Hospital of the Faculty of Medicine of Ribeirao Preto, University of São Paulo (HCFMRP-USP) was revised. The mean $( \pm \mathrm{SD}$ ) age at the time of HCC diagnosis was $55.6 \pm 11.2$ years, with $81.5 \%$ of them being males. Cirrhosis was present in $89.2 \%$ of cases, with $53.4 \%$ of 
the patients being ChildPugh A; chronic hepatitis B or C without cirrhosis was detected in $3.2 \%$, nonalcoholic steatohepatitis (NASH) in 3.8\%, and a normal liver in $3.8 \%$ [5].

The human major histocompatibility complex (MHC) represents a set of genes responsible for coding histocompatibility molecules. It is a high density region [3.6 Mb DNA) located on the short arm of chromosome 6, region 6p21.3, which contains more than 200 genes grouped into three classes denoted class I, II and III. Class I genes (classic or class Ia) code for the classic histocompatibility molecules HLA-A, B and C; class II genes code for the histocompatibility molecules HLA-DR, DQ and DP, and class III genes, although included in the MHC, do not code for histocompatibility molecules. Among class I genes, there are also those denoted non-classic or class $\mathrm{Ib}$, which code for the non-classic histocompatibility molecules HLA-E, F and G [6].

HLA-G is a class I non-classic HLA gene consisting of eight exons and seven introns with a stop codon in exon 6 (exon 7 is always absent from mature mRNA and, due to the stop codon in exon 6, exon 8 is not translated), a 5' promoter region and a $3^{\prime}$ untranslated region (3'UTR) $[7,8]$. The characteristics of $H L A-G$ are: low polymorphism, alternative splicing in the primary transcript that codes for seven protein isoforms, limited distribution in normal tissues, and immunsuppressive properties [9]. Of the seven proteins coded by the HLA-G gene, four are linked to the membrane (HLA-G1 to HLA-G4) and three are soluble (HLAG5 to HLA-G7). The HLA-G1 and HLA-G5 proteins are the main isoforms described in healthy issues such as trophoblast, thymus, cornea, and erythroid and endothelial precursors. On the other hand, the expression of $H L A-G$ can be induced in pathological situations such as autoimmune and inflammatory diseases, viral infections, cancer, and transplantation. HLA-G exerts inhibitory activity by binding to inhibitory receptors denoted immunoglobulin-like transcript (ILT)-2 and ILT-4, which are expressed by lymphoid and myeloid cells and by myeloid cells only, respectively, and killer immunoglobulin-like (KIR)2DL4 receptor, present only in natural killer cells [9].

Thus far, 47 alleles have been attributed to the HLA-G gene, which code for 15 distinct functional proteins with all isoforms $\left(H L A-G^{*} 01: 01,{ }^{*} 01: 02,{ }^{*} 01: 03,{ }^{*} 01: 04,{ }^{*} 01: 06,{ }^{*} 01: 07,{ }^{*} 01: 08\right.$, ${ }^{*} 01: 09,{ }^{*} 01: 10,{ }^{*} 01: 11,{ }^{*} 01: 12,{ }^{*} 01: 14,{ }^{*} 01: 15,{ }^{*} 01: 16$, and ${ }^{*} 01: 17$ ) and truncated (G*01:05N allele) or no proteins at all ( $\mathrm{G}^{*} 01: 13 \mathrm{~N}$ allele). Polymorphic sites are observed in the coding and noncoding regions. The promoter and 3'UTR regions of HLA-G are highly polymorphic, with the variations in the $3^{\prime}$ UTR being associated with the levels of $H L A-G$ expression. Two main polymorphic sites were identified in the 3'UTR: a 14bp insertion/deletion, in which the insertion has been associated with reduced levels of HLA-G, and the presence of guanine at position +3142 , which increases the affinity of specific microRNAs for HLA-G mRNA, reducing the expression of HLA-G $[8,10]$.

The expression of $H L A-G$ is frequently detected in malignant tumors of various origins and in some situations has been significantly correlated with tumor size, degree of invasion, metastasis, clinical stages of the disease, and mortality [11,12]. Regarding HCC, few studies evaluating the role of alleles and genotypes of $H L A-G$ polymorphism are available in the literature, and evolve different population. Jiang et al, studying a Chinese population showed that the heterozygote and the 14bp II homozygote confer a lower risk of HCC compared with 
$14 \mathrm{bp} \mathrm{DD}$, and that the associations were stronger in the hepatitis B-positive than the hepatitis B-negative population [13] Zhang et al, examining fifteen single-nucleotide polymorphisms (SNPs) in the non-classical class I alleles, found that the SNPs rs17875380, rs41557518, rs114465251, and rs115492845 were associated with susceptibility to chronic hepatitis B infection or HCC, and HLA-F*01:04, HLA-G*01:05N, and HLA-E*01:01 were associated with hepatitis B or hepatitis B with HCC [14].

In general, the inflammatory response mediated by the immune system is beneficial to the host; however, when tissue homeostasis is chronically affected the interactions between innate and adaptive immune responses may be deregulated, culminating with chronic inflammation, excessive tissue remodeling, loss of tissue architecture, apoptosis/necrosis and oxidative stress which, under certain circumstances, may increase the risk of tumor development [15]. The cytokines are responsible for the regulation of growth differentiation and activation of immune cells. The ability to produce cytokines by an individual is influenced by genetic components that have been attributed to molecular mechanisms, including variations in the transcription, translation and secretion pathways [16].

\section{Problem statement}

Over the last years, regarding HCC, few studies evaluating the role of alleles and genotypes of HLA-G polymorphism are available in the literature, and included diverse patient populations. Moreover, previous studies have concentrated on cytokine promoters, encouraged by the identification of a series of SNPs [17]. However, the relation of these polymorphisms with susceptibility to HCC or disease severity has not been clarified.

\section{Application area}

Immune response and carcinogenesis

\section{Research course}

Alleles and genotypes of cytokines polymorphisms and 14bp of HLA-G gene in HCC patients.

\section{Method and patients}

We evaluated, in a Brazilian cohort, the association of alleles and genotypes of the 14bp insertion/deletion polymorphism of the $H L A-G$ gene, and alleles and genotypes of polymorphisms of genes IL-18 (-607 C/A; rs1946518 and -137 C/G; rs187238), IFN- $\gamma$ (+874 A/T; rs62559044) and TNF- $\alpha$ (-238 A/G; rs361525 and -308 A/G; rs1800629) with susceptibility to HCC and with the type of tumor presentation (infiltrative diffuse, multinodular and uninodular), with nodule size $(>10 \mathrm{~cm}, 5-10 \mathrm{~cm}$ and $<5 \mathrm{~cm})$, with the Milan criteria (fulfills or does not fulfill), the evaluation of metastasis (present or absent), and the histological classification of the tumor (Edmondson-Steiner Classification) [18,19, 20,21]. 
This was a retrospective cross-sectional study conducted on 109 patients (89 men) with mean age $55.8 \pm 11.4$ years for the $14 \mathrm{bp}$ insertion/deletion polymorphism of the HLA-G gene, and 112 consecutive patients [Mean $( \pm \mathrm{SD})$ age was $55.6 \pm 11.2$ years, and $81.5 \%$ were males] for the polymorphisms of genes IL-18 (-607 C/A; rs1946518 and -137 C/G; rs187238), IFN- $\gamma$ (+874 A/T; rs62559044) and TNF- $\alpha$ (-238 A/G; rs361525 and -308 A/G; rs1800629) followed up from 2001 to 2009 at the Focal Hepatic Injuries Outpatient Clinic of the Faculty of Medicine of Ribeirão Preto, University of São Paulo (HCFMRP-USP). The study was approved by the Research Ethics Committee of HCFMRP-USP. Individuals of both genders who fulfilled the following criteria were included in the study: a) diagnosis of HCC defined by the Barcelona 2000 criteria [22] for the diagnoses performed up to 2006 and according to the recommendations of the American Association for the Study of Liver Disease (AASLD) [23] for the diagnoses performed since 2007; b) with DNA stored in the Biological Sample Bank of the Laboratory of Gastroenterology, Department of Internal Medicine. Exclusion criteria were patients with focal hepatic injuries other than HCC according to the Barcelona 2000 criteria and the recommendations of the AASLD and patients with other concomitant neoplasias.

The evaluation of the severity of HCC was based on: a) tumor presentation (uninodular, multinodular or diffuse infiltrative); b) nodule size ( $<5 \mathrm{~cm}, 5-10 \mathrm{~cm}$ or $>10 \mathrm{~cm}) ; \mathrm{c}$ ) Milan criteria (fulfills or does not fulfill); d) metastasis (present or absent); e) histological classification according to Edmondson \& Steiner, 1954 (grades I, II, III or IV) [24].

A total of 202 healthy individuals (56 females and 146 males) with a mean age $( \pm S D)$ of $33.3 \pm 8.3$ years and from the same geographic region as the patients studied were used as controls for the evaluation of the frequency of $14 \mathrm{bp}, I L-18, I F N-\gamma$ and TNF- $\alpha$ alleles and genotypes.

For the determination of the 14bp insertion/deletion, IL-18 (-607 C/A; rs1946518 and -137 C/G; rs187238), IFN- $\gamma$ (+874 A/T; rs62559044) and TNF- $\alpha$ (-238 A/G; rs361525 and $-308 \mathrm{~A} / \mathrm{G}$; rs1800629) genotypes, we first extracted genomic DNA from peripheral leukocytes by the salting out technique [25]. The HLA-G 14bp insertion/deletion genotypes at exon 8 of the HLAG locus was analyzed as described: $200 \mathrm{ng}$ of genomic DNA were amplified in a $25 \mathrm{~mL}$ reaction mixture containing $0.20 \mathrm{mM}$ dNTP (Invitrogen, Carlsbad, CA), $0.2 \mathrm{mM}$ of each primer, $0.5 \mathrm{U}$ Taq DNA polymerase (Invitrogen, Carlsbad, CA), $1.5 \mathrm{mM} \mathrm{MgCl} 2$ and a $1 x$ PCR buffer $(0.2 \mathrm{M}$ Tris- $\mathrm{HCl}, \mathrm{pH} 8.5 ; 0.5 \mathrm{M} \mathrm{KCl})$. After an initial denaturation step at $94^{\circ} \mathrm{C}$ for 5 minutes, samples were submitted to 30 additional cycles at $94^{\circ} \mathrm{C}$ for 45 seconds, $56^{\circ} \mathrm{C}$ for 45 seconds and $72^{\circ} \mathrm{C}$ for 1 minute, with a final extension cycle at $72^{\circ} \mathrm{C}$ for 7 minutes with $5^{\prime}$-TGTGAAACAGCTGCCCTGTG-3' as the forward primer and ' ${ }^{\prime}$-AAGGAATGCAGTTCAGCATGA-3' as the reverse primer [26,27]. After DNA amplification by PCR, the reaction products were submitted to $10 \%$ polyacrylamide gel electrophoresis under non-denaturing conditions followed by silver impregnation. The presence of $345 \mathrm{bp}$ fragments corresponded to the deletion allele, while the $359 \mathrm{bp}$ fragment corresponded to the $14 \mathrm{bp}$ insertion allele.

The alleles and genotypes of IL-18 (-607 C/A; rs1946518 and -137 C/G; rs187238), IFN- $\gamma$ (+874 $\mathrm{A} / \mathrm{T} ; \mathrm{rs} 62559044)$ and TNF- $\alpha$ (-238 A/G; rs361525 and -308 A/G; rs1800629) polymorphisms were analyzed by the polymerase chain reaction using allele-specific primers (PCRSSP) (Table 1). For SNP IL-18 -607, a generic reverse primer 5'-TAACCTCATTCAGG 


\begin{tabular}{|c|c|c|}
\hline SNP & Primer & Sequence $\left(5^{\prime}-3^{\prime}\right)$ \\
\hline \multirow[t]{5}{*}{ IL-18 -607 C/A } & IL-18 607.2 & TAACCTCATTCAGGACTTCC \\
\hline & IL-18 607C & GTTGCAGAAAGTGTAAAAATTATTAC \\
\hline & IL-18 607A & GTTGCAGAAAGTGTAAAAATTATTAA \\
\hline & HGBA.S & CGGTATTTGGAGGTCAGCAC \\
\hline & HGBA.A & CCCACCACCAAGACCTACTT \\
\hline \multirow[t]{5}{*}{ IL-18-137 C/G } & IL-18 137.2 & AGGAGGGCAAAATGCACTGG \\
\hline & IL-18 137C & CCCCAACTTTTACGGAAGAAAAC \\
\hline & IL-18 137G & CCCCAACTTTTACGGAAGAAAAG \\
\hline & HGBA.S & CGGTATTTGGAGGTCAGCAC \\
\hline & HGBA.A & CCCACCACCAAGACCTACTT \\
\hline \multirow[t]{5}{*}{$I F N-\gamma+874 \mathrm{~A} / \mathrm{T}$} & IFN- $\gamma 874$ & TCAACAAAGCTGATACTCCA \\
\hline & IFN- $\gamma 874 \mathrm{~T}$ & TTCTTACAACACAAAATCAAATCT \\
\hline & IFN- $\gamma 874 \mathrm{~A}$ & TTCTTACAACACAAAATCAAATCA \\
\hline & $\mathrm{GH} 1$ & GCCTTCCCAACCATTCCCTTA \\
\hline & $\mathrm{GH} 2$ & TCACGGATTTCTGTTGTGTTTC \\
\hline \multirow[t]{5}{*}{$T N F-a-238 \mathrm{~A} / \mathrm{G}$} & TNF 238 UP & AGGCAATAGGTTTTTGAGGGCCAT \\
\hline & TNFAS238G & CCCCATCCTCCCTGCTCC \\
\hline & TNFAS238A & TCCCCATCCTCCСТGСTCT \\
\hline & HGBA.S & CGGTATTTGGAGGTCAGCAC \\
\hline & HGBA.A & CCCACCACCAAGACCTACTT \\
\hline \multirow[t]{5}{*}{$T N F-a-308 \mathrm{~A} / \mathrm{G}$} & TNFAA 308.2 & CAGCGGAAAACTTCCTTGGT \\
\hline & TNFAS 308G & ATAGGTTTTTGAGGGGCATGG \\
\hline & TNFAS 308A & ATAGGTTTTGAGGGGCATGA \\
\hline & HGBA.S & CGGTATTTGGAGGTCAGCAC \\
\hline & HGBA.A & CCCACCACCAAGACCTACTT \\
\hline
\end{tabular}

IL-18: interleukin-18; IFN- $\gamma$ : interferon-gamma; TNF-a: tumor necrosis factor-alpha; HGBA.S and HGBA.A: human hemoglobin; $\mathrm{GH} 1$ and GH2: human growth hormone.

Table 1. Primers for the detection of single nucleotide polymorphisms (SNPs) of genes IL-18 (-607 C/A and -137 C/G), IFN- $\gamma(+874$ A/T) and TNF- $a(-238$ A/G and -308 A/G).

ACTTCC- $3^{\prime}$ and two allele-specific forward primers (5'-GT TGCAGAAAGTGTAAAAATTATTAC- $3^{\prime}$ and $5^{\prime}$-GTTGCAG AAAGTGTAAAAATTATTAA- $3^{\prime}$ ) were used to amplify a 196-bp product. For SNP IL-18 -137, a common reverse primer 5'-AGGAGGGCAAAATGCACTGG-3' and two allele-specific forward primers (5'-CCCCAACTTTTACGGAAG AAAAG-3' and $5^{\prime}$-CCCCAACTTTTACGGAAGAAAAC-3') were used to amplify a 261- 
bp product. An internal positive amplification control was performed using the primers $5^{\prime}$ CG GTATTTGGAGGTCAGCAC-3' and 5'-CCCACCACCAAGA CCTACTT-3', which are specific for the human hemoglobin genes. The reactions were performed in a final volume of $10 \mu \mathrm{L}$ containing 200ng of genomic DNA, 3pmol of each primer (the generic one and a specific one), $2 \mathrm{pmol}$ of each control primer, $0.25 \mathrm{mM}$ dNTP (Pharmacia Biotech, Paris, France), $1.5 \mathrm{mM} \mathrm{MgCl} 2,0.75 \mathrm{U}$ of Taq DNA poly- merase (Invitrogen, Carlsbad, CA), and $1 \times$ PCR buffer $(0.2 \mathrm{M}$ Tris $-\mathrm{HCl}, \mathrm{pH} 8.5,0.5 \mathrm{M} \mathrm{KCl})$. The cyclingconditions were $3 \mathrm{~min}$ at $94^{\circ} \mathrm{C}$, followed by seven cycles of $20 \mathrm{~s}$ at $94^{\circ} \mathrm{C}, 40 \mathrm{~s}$ at $64^{\circ} \mathrm{C}$ for IL18 -607 or $60 \mathrm{~s}$ at $68^{\circ} \mathrm{C}$ for IL18 -137 and $40 \mathrm{~s}$ at $72^{\circ} \mathrm{C}$ and 25 cycles of $20 \mathrm{~s}$ at $94^{\circ} \mathrm{C}, 40 \mathrm{~s}$ at $57^{\circ} \mathrm{C}$ for IL18 -607 or $20 \mathrm{~s}$ at $62^{\circ} \mathrm{C}$ for IL18 -137 and $40 \mathrm{~s}$ at $72^{\circ} \mathrm{C}$, and final stage of $5 \mathrm{~min}$ at $72^{\circ} \mathrm{C}$ [9]. For the TNF- $\alpha(-238$ and -308$)$ and IFN- $\gamma+874$ specific amplification, the primers were identical to those previously described [28,29]. All amplification products were visualized using $10 \%$ nondenaturing polyacrylamide gel electrophoresis (PAGE) followed by silver staining.

For statistical analysis, the allele and genotype frequencies were calculated by the direct count method in all groups. Adherence of genotypic proportions to Hardy-Weinberg expectations was determined by the exact test of Guo and Thompson [30] using the GENEPOP software v. 4.0.10. The presence of a significant association between polymorphisms of the same gene was evaluated by a likelihood ratio test of probability of linkage disequilibrium using the ARLEQUIN software, v. 3.1 [31]. If a positive association was detected, but the gameteic phase was unknown, the PHASE (v. 2 package) [32] and EM algorithms [33] were used to reconstruct the TNF or IL haplotypes. Allele, genotype and haplotype frequencies were compared by the twotailed Fisher exact test using the GraphPad InStat 3.06 software, which was also used to estimate the odds ratio (OR) and its $95 \%$ confidence interval $(95 \% \mathrm{CI})$. The level of significance was set at $\mathrm{P}<0.05$.

\section{Results}

Cirrhosis was observed in $89 \%$ of the patients, and major underlying causes included: hepatitis C (35\%), alcohol plus hepatitis C (25\%), alcohol (18\%), hepatitis B $(9 \%)$, alcohol plus hepatitis B (4\%), alcohol plus hepatitis C plus hepatitis B (1\%), hereditary hemochromatosis $(1 \%)$, non-alcoholic steatohepatitis $(1 \%)$, autoimmune hepatitis $(1 \%)$ and cryptogenic cirrhosis (5\%). Four percent of the patients had no underlying liver disease, $4 \%$ nonalcoholic steatohepatitis and 3\% chronic hepatitis without cirrhosis (two hepatitis B and one hepatitis C). Fifty-four percent (59/109) of the patients met the Milan criteria for liver transplantation [34]. Metastasis search was performed in $88 \%$ of cases (17\% had metastasis and $93 \%$ did not). Tumors $<5 \mathrm{~cm}, 5-10 \mathrm{~cm}$ and $>10 \mathrm{~cm}$ were found in $57 \%, 18 \%$ and $8 \%$ respectively. Diffuse infiltrative HCC totaled $15 \%$ of the cases. Histological evaluation of HCC was performed in 39\% (42/109) of subjects with 62\% presenting Edmondson-Steiner I or II and $38 \%$ III or IV. 


\subsection{4bp insertion/deletion polymorphism}

Genotype frequencies of patient and control groups were in accordance to Hardy-Weinberg Equilibrium. The $14 \mathrm{bp}^{*} \mathrm{D}$ allele was more frequent in cases of HCC than in controls ( $0.6514 \mathrm{vs}$. $0.5619 ; P=0.0326)$, conferring an $\mathrm{OR}=1.46$ ( $95 \% \mathrm{CI}=1.04-2.05)$. Evaluation of genotype frequency (genotypes $14 \mathrm{pb} \mathrm{DD}, \mathrm{DI}$ and II) did not show significant difference between the groups studied $(P=0.0871 ; \mathrm{OR}=1.54 ; 95 \% \mathrm{CI}=0.96-2.48 ; P=0.7182 ; \mathrm{OR}=0.89 ; 95 \% \mathrm{CI}=0.56-1.44 ;$ and $P=0.1343$; $\mathrm{OR}=0.60 ; 95 \% \mathrm{CI}=0.32-1.12$, respectively). However, the $14 \mathrm{bp}$ DD genotype was marginally more frequent among individuals with HCC than among controls, with $10.3 \%$ difference ( 0.4495 vs. 0.3465 , respectively) $(P=0.0871 ; \mathrm{OR}=1.54 ; 95 \% \mathrm{CI}=0.96-2.48)$. Patients were stratified according to the characteristics of HCC (type of tumor presentation, nodule size, Milan criteria, presence of metastasis and Edmondson-Steiner classification), and no significant differences were detected between groups regarding the $14 \mathrm{bp}$ insertion/deletion allele frequencies (14bp* D and 14bp*I alleles) or genotype frequencies (14bp DD, DI and II genotypes). Table 2 shows the frequency of the $14 \mathrm{bp}$ insertion/deletion polymorphism and Table 3 shows the results of the statistical analyses.

\begin{tabular}{|c|c|c|c|c|c|}
\hline \multirow{2}{*}{$\frac{\text { Samples }}{\mathrm{I}}$} & \multicolumn{2}{|c|}{$14 \mathrm{bp}$ alleles } & \multicolumn{3}{|c|}{ 14bp genotypes } \\
\hline & $D$ & II & $\mathrm{DI}$ & DD & \\
\hline Groups & $\mathrm{n}$ (frequency) & $\mathrm{n}$ (frequency) & $\mathrm{n}$ (frequency) & n(frequency) & $\mathrm{n}$ (frequency) \\
\hline Control & $177[0.4381]$ & 227 [0.5619] & $45[0.2228]$ & 87 [0.4307] & 70 [0.3465] \\
\hline $\mathrm{HCC}$ & $76[0.3486]$ & $142[0.6514]$ & $16[0.1468]$ & $44[0.4037]$ & 49 [0.4495] \\
\hline \multicolumn{6}{|l|}{ Tumor presentation } \\
\hline Diffuse & $7[0.2500]$ & $21[0.7500]$ & $1[0.0714]$ & $5[0.3571]$ & $8[0.5714]$ \\
\hline Multinodular & $14[0.3684]$ & $24[0.6316]$ & 13 [0.1579] & $9[0.4211]$ & $6[0.4211]$ \\
\hline Uninodular & $55[0.3667]$ & 95 [0.6333] & $12[0.1600]$ & 31 [0.4133] & $32[0.4767]$ \\
\hline \multicolumn{6}{|l|}{ Nodule size } \\
\hline$>10 \mathrm{~cm}$ & 6 [0.3333] & 12 [0.6667] & $1[0.1111]$ & 4 [0.4444] & $4[0.4444]$ \\
\hline $5-10 \mathrm{~cm}$ & $11[0.2750]$ & $29[0.7250]$ & $1[0.0500]$ & $9[0.4500]$ & $10[0.5000]$ \\
\hline$<5 \mathrm{~cm}$ & 51 [0.4113] & 73 [0.5887] & 13 [0.2097] & 25 [0.4032] & 24 [0.3871] \\
\hline \multicolumn{6}{|l|}{ Metastasis } \\
\hline Present & $4[0.2857]$ & 10 [0.7143] & $0[0.0000]$ & $4[0.5714]$ & $3[0.4286]$ \\
\hline Absent & 63 [0.3539] & $115[0.6461]$ & 13 [0.1461] & 37 [0.4157] & 39 [0.4382] \\
\hline \multicolumn{6}{|l|}{ Milan criteria } \\
\hline Yes & $46[0.3898]$ & 72 [0.6102] & $11[0.1864]$ & $24[0.4068]$ & $24[0.4068]$ \\
\hline No & 30 [0.3000] & 70 [0.7000] & $5[0.1000]$ & $20[0.4000]$ & 25 [0.5000] \\
\hline \multicolumn{6}{|l|}{ Edmondson } \\
\hline$I-I \mid$ & $24[0.4615]$ & 28 [0.5385] & $5[0.1923]$ & 14 [0.5385] & $7[0.2692]$ \\
\hline III-IV & $16[0.5000]$ & $16[0.5000]$ & $4[0.2500]$ & $8[0.5000]$ & $4[0.2500]$ \\
\hline
\end{tabular}

HLA-G: Human Leukocyte Antigen-G; bp: base pairs; HCC: hepatocellular carcinoma; I: insertion; D:deletion

Table 2. Distribution of the HLA-G 14bp insertion/deletion allele and genotype frequencies. 


\begin{tabular}{|c|c|c|c|c|c|}
\hline \multirow{2}{*}{ Comparisons } & \multicolumn{2}{|c|}{$14 \mathrm{bp}$ alleles } & \multicolumn{3}{|c|}{ 14bp genotypes } \\
\hline & $\mathrm{D}$ & ॥ & $\mathrm{DI}$ & DD & \\
\hline \multicolumn{6}{|l|}{ Groups } \\
\hline HCC vs. control & 0.0326 & $0.0326 a$ & 0.1343 & 0.7182 & $0.0871 \mathrm{~b}$ \\
\hline \multicolumn{6}{|l|}{ Tumor presentation } \\
\hline Diffuse vs. multinodular & 0.4238 & 0.4238 & 0.6197 & 1,0000 & 0.4905 \\
\hline Diffuse vs. uninodular & 0.2839 & 0.2839 & 0.6830 & 0.7738 & 0.3863 \\
\hline Multinodular vs. uninodular & 1.0000 & 1.0000 & 1.0000 & 1.0000 & 1.0000 \\
\hline \multicolumn{6}{|l|}{ Nodule size } \\
\hline$>10 \mathrm{~cm}$ vs. $5-10 \mathrm{~cm}$ & 0.7577 & 0.7577 & 0.5320 & 1.0000 & 1.0000 \\
\hline$>10 \mathrm{~cm}$ vs. $<5 \mathrm{~cm}$ & 0.6132 & 0.6132 & 0.6769 & 1.0000 & 0.7318 \\
\hline $5-10 \mathrm{~cm}$ vs. $<5 \mathrm{~cm}$ & 0.1372 & 0.1372 & 0.1698 & 0.7963 & 0.4382 \\
\hline \multicolumn{6}{|l|}{ Milan criteria } \\
\hline Yes vs. no & 0.1995 & 0.1995 & 0.2794 & 1.0000 & 0.3421 \\
\hline \multicolumn{6}{|l|}{ Metastasis } \\
\hline Present vs. Absent & 0.7739 & 0.7739 & 0.5883 & 0.4556 & 1.0000 \\
\hline \multicolumn{6}{|l|}{ Edmondson-Steiner } \\
\hline I-II vs. III-IV & 0.8232 & 0.8232 & 0.7109 & 1.0000 & 1.0000 \\
\hline \multicolumn{6}{|c|}{$\begin{array}{l}\text { HLA-G: Human Leukocyte Antigen-G; bp: base pairs; HCC: hepatocellular carcinoma; I: insertion; D:deletion } \\
\text { a Odds ratio= } 1.46 \text { [95\% confidence interval: } 1.04-2.05]\end{array}$} \\
\hline b Odds ratio $=1.54$ [95\% confidence $\mathrm{i}$ & $96-2.48]$ & & & & \\
\hline
\end{tabular}

Table 3. Probability values obtained by means of two-tailed Fisher exact test in the comparisons of HLA-G 14bp insertion/deletion allele and genotype frequencies between different groups.

\subsection{IL-18 (-607 C/A; rs1946518 and -137 C/G; rs187238), IFN- $\gamma$ (+874 A/T; rs62559044) and TNF- $\alpha$ (-238 A/G; rs361525 and -308 A/G; rs1800629) polymorphism}

The genotypification of the polymorphisms of the genes IL-18 (-607 C/A and -137 C/G), IFN- $\gamma$ $(+874 \mathrm{~A} / \mathrm{T})$ and TNF- $\alpha(-238 \mathrm{~A} / \mathrm{G}$ and $-308 \mathrm{~A} / \mathrm{G})$ was performed in 112 patients with HCC and in 202 healthy controls. The genotype distribution of the two groups adhered to the theoretical proportions of Hardy-Weinberg equilibrium. Significant associations were detected between HCC and the following alleles (Table 4): $I L-18-607^{*} \mathrm{~A}(P=0.0235 ; \mathrm{OR}=1.48 ; 95 \% \mathrm{CI}=1.06-2.08)$; TNF- $\alpha-238^{*} \mathrm{~A}(P=0.0025 ; \mathrm{OR}=2.12 ; 95 \% \mathrm{CI}=1.32-3.40)$, and TNF- $\alpha-308^{*} \mathrm{~A}(P=0.0351 ; \mathrm{OR}=1.82$; $95 \% \mathrm{CI}=1.07-3.08$ ). When the genotypes were evaluated (Table 5), the following associations with HCC were detected: $I L-18-607$ AA ( $P=0.0048$; OR=3.03; 95\%CI=1.40-6.55); TNF- $\alpha-238$ GA $(P=0.0011 ; \quad O R=2.44 ; \quad 95 \% C I=1.45-4.12) ; \quad$ and $T N F-\alpha \quad-308$ GA $\quad(P=0.0031 ; \quad O R=2.51 ;$ $95 \% \mathrm{CI}=1.39-4.51)$. Alleles and genotypes from $I L-18-137 \mathrm{G} / \mathrm{C}$ and $I F N \gamma+874 \mathrm{~T} / \mathrm{A}$ were not 
associated with susceptibility to HCC. The inference of haplotypes was performed for the polymorphisms of IL-18 and TNF- $\alpha$. Haplotypes -607A/-137G IL-18 and TNF- $\alpha$-308G/-238A $-308 \mathrm{~A} /-238 \mathrm{G}$ were more frequent in patients with HCC compared with the control group $(\mathrm{P}=$ $0.0180, \mathrm{OR}=1.69,95 \% \mathrm{CI} 1.10$ to $2.59, \mathrm{P}=0.0036, \mathrm{OR}=2.06,95 \% \mathrm{CI} 1,28-3.31$ and $\mathrm{P}=0.0480$, $\mathrm{OR}=1.75 ; 95 \% \mathrm{CI}=1.03$ to 2.97 , respectively). On the other hand, TNF- $\alpha-308 \mathrm{G} /-238 \mathrm{G}$ haplotype was more frequent in the group of healthy subjects $(\mathrm{P}=0.0001, \mathrm{OR}=0.46,95 \% \mathrm{CI} 0.32$ to 0.68$)$, providing protection against HCC.

\begin{tabular}{|c|c|c|c|c|c|c|}
\hline \multirow[t]{2}{*}{ SNP } & \multicolumn{5}{|c|}{ Allele frequency } & \multirow[b]{2}{*}{$95 \% \mathrm{Cl}$} \\
\hline & allele & $\begin{array}{l}\mathrm{HCC} \\
\mathrm{n} \text { (frequency) }\end{array}$ & $\begin{array}{l}\text { Control } \\
\text { n (frequency) }\end{array}$ & $P$ & OR & \\
\hline \multirow[t]{2}{*}{ IL-18-137C/G } & C & $62[0.2768]$ & $120[0.2970]$ & 0.6464 & 0.90 & $0.63-1.30$ \\
\hline & G & $162[0.7232]$ & $284[0.7030]$ & 0.6464 & 1.10 & $0.77-1.59$ \\
\hline \multirow[t]{2}{*}{ IL-18-607A/C } & A & 92 [0.4107] & $129[0.3193]$ & 0.0235 & 1.48 & $1.06-2.08$ \\
\hline & C & 132 [0.5893] & 275 [0.6807] & 0.0235 & 0.67 & $0.48-0.94$ \\
\hline \multirow[t]{2}{*}{ IFN- $-\gamma+874 \mathrm{~A} / \mathrm{T}$} & $A$ & $130[0.5856]$ & $240[0.5941]$ & 0.8652 & 0.96 & $0.69-1.35$ \\
\hline & $\mathrm{T}$ & $92[0.4144]$ & $164[0.4059]$ & 0.8652 & 1.03 & $0.74-1.44$ \\
\hline \multirow[t]{2}{*}{$T N F-a-238 A / G$} & $A$ & $41[0.1847]$ & 39 [0.0965] & 0.0025 & 2.12 & $1.32-3.40$ \\
\hline & G & $181[0.8153]$ & 365 [0.9035] & 0.0025 & 0.47 & $0.29-0.76$ \\
\hline \multirow[t]{2}{*}{$T N F-a-308 A / G$} & $A$ & $30[0.1351]$ & $32[0.0792]$ & 0.0351 & 1.82 & $1.07-3.08$ \\
\hline & G & 192 [0.8649] & 372 [0.9208] & 0.0351 & 0.55 & $0.32-0.93$ \\
\hline
\end{tabular}

Table 4. Distribution of the allele frequencies of polymorphisms of the IL-18 (-607 C/A and -137 C/G), IFN- $\gamma$ (+874 $\mathrm{A} / \mathrm{T})$, and TNF- $a(-238 \mathrm{~A} / \mathrm{G}$ e $-308 \mathrm{~A} / \mathrm{G})$ genes among patients with hepatocellular carcinoma (HCC) and healthy controls.

When the -607C/A SNP of $I L-18$ was evaluated in terms of the different presentations of the HCC, the frequencies of the $-607^{*} \mathrm{C}$ and $-607^{*} \mathrm{~A}$ alleles between individuals with multinodular and uninodular HCC, showed that the $-607^{*} \mathrm{C}$ allele confers significant susceptibility to multinodular lesions $(P=0.0289 ; \mathrm{OR}=2.4 ; 95 \% \mathrm{CI}=1.09-5.28)$. Evaluation of the genotype frequency in SNP $-607 \mathrm{C} / \mathrm{A}$ of $I L-18$ revealed that genotype 607CC was significantly more frequent in cases of multinodular HCC compared to uninodular tumors $(P=0.0284$; OR=3.5; $95 \% \mathrm{CI}=1.24-9.86)$. On the other hand, genotype +874AT was found to be more frequent among patients with infiltrative diffuse HCC compared to uninodular HCC $(P=0.0443$; OR=3.6; $95 \% \mathrm{CI}=1.04-12.47$ ), thus conferring greater susceptibility to the diffuse tumor. 


\begin{tabular}{|c|c|c|c|c|c|c|}
\hline \multirow[t]{2}{*}{ SNP } & \multicolumn{4}{|c|}{ Genotype frequency } & \multirow[b]{2}{*}{ OR } & \multirow[b]{2}{*}{$95 \% \mathrm{Cl}$} \\
\hline & genotype & $\begin{array}{c}\text { HCC } \\
\mathrm{n} \text { (frequency) }\end{array}$ & $\begin{array}{c}\text { Control } \\
\text { n (frequency) }\end{array}$ & $P$ & & \\
\hline \multirow[t]{3}{*}{ IL-18-137C/G } & CG & $48[0.4286]$ & $84[0.4185]$ & 0.9051 & 1.05 & $0.66-1.68$ \\
\hline & CC & $7[0.0625]$ & $18[0.0891]$ & 0.5157 & 0.68 & $0.27-0.68$ \\
\hline & GG & 57 [0.5089] & $100[0.4950]$ & 0.9063 & 1.06 & $0.67-1.68$ \\
\hline \multirow[t]{3}{*}{ IL-18-607A/C } & CA & $56[0.5000]$ & $105[0.5198]$ & 0.8138 & 0.92 & $0.58-1.47$ \\
\hline & AA & $18[0.1607]$ & $12[0.0594]$ & 0.0048 & 3.03 & $1.40-6.55$ \\
\hline & $\mathrm{CC}$ & 38 [0.3393] & $85[0.4208]$ & 0.1845 & 0.71 & $0.44-1.14$ \\
\hline \multirow{3}{*}{$I F N-\gamma+874 A / T$} & AT & $50[0.4505]$ & 82 [0.4059] & 0.4741 & 1.20 & $0.75-1.91$ \\
\hline & AA & $40[0.3604]$ & $79[0.3911]$ & 0.6276 & 0.88 & $0.54-1.42$ \\
\hline & $\mathrm{TT}$ & $21[0.1892]$ & $41[0.2030]$ & 0.8823 & 0.92 & $0.91-1.65$ \\
\hline \multirow[t]{3}{*}{$T N F-a-238 A / G$} & GA & $41[0.3694]$ & $39[0.1931]$ & 0.0011 & 2.44 & $1.45-4.12$ \\
\hline & AA & $0[0.0000]$ & $0[0.0000]$ & 1.0000 & 1.81 & $0.03-92.15$ \\
\hline & GG & $70[0.6306]$ & $163[0.8069]$ & 0.0011 & 0.40 & $0.24-0.69$ \\
\hline \multirow[t]{3}{*}{$T N F-a-308 \mathrm{~A} / \mathrm{G}$} & GA & $30[0.2703]$ & $26[0.1287]$ & 0.0031 & 2.51 & $1.39-4.51$ \\
\hline & AA & $0[0.0000]$ & 3 [0.0149] & 0.5548 & 0.25 & $0.01-4.99$ \\
\hline & GG & $81[0.7297]$ & $173[0.8564]$ & 0.0098 & 0.45 & $0.25-0.80$ \\
\hline
\end{tabular}

Table 5. Distribution of the genotype frequencies of polymorphisms of the IL-18 (-607 C/A and $-137 \mathrm{C} / \mathrm{G})$, IFN- $\gamma(+874$ $\mathrm{A} / \mathrm{T})$, and TNF- $a(-238 \mathrm{~A} / \mathrm{G}$ and $-308 \mathrm{~A} / \mathrm{G})$ genes among patients with hepatocellular carcinoma (HCC) and healthy controls.

No significant differences in the allele or genotype frequencies of SNPs of $I L-18, I F N-\gamma$ and TNF- $\alpha$ were detected between the various tumor sizes, although the TNF- $\alpha-238^{*} \mathrm{~A}$ allele was slightly more frequent in tumors larger than $10 \mathrm{~cm}$ compared to tumors smaller than $5 \mathrm{~cm}$ $(P=0.0889 ;$ OR=2.82; 95\%CI: 0.94-8.41). Similarly, genotype TNF- $\alpha-238$ AG indicated a marginally greater susceptibility to tumors $>10 \mathrm{~cm}(P=0.0565 ; \mathrm{OR}=4.63 ; 95 \% \mathrm{CI}=1.05-20.48)$ than to tumors $<5 \mathrm{~cm}$, whereas genotype TNF- $\alpha$-238GG conferred marginal protection against large lesions ( $>10 \mathrm{~cm}$ vs. $<5 \mathrm{~cm})(P=0.0565 ; \mathrm{OR}=0.22 ; 95 \% \mathrm{CI}=0.05-0.95)$.

Evaluation of SNP -607C/A of IL-18 revealed no significant difference in allele and genotype frequencies between patients with HCC with or without metastasis. In contrast, evaluation of SNP $-137 C / G$ of $I L-18$ revealed that the $-137^{*} \mathrm{C}$ allele was more frequent among individuals with metastasis than among individuals with no meatastasis $(P=0.0240 ; \mathrm{OR}=4.00$; 95\%CI=1.32-12.14). The frequencies of genotypes -137CC, CG or GG did not differ significantly between patients with and without metastasis, although genotype -137CC tended to confer greater susceptibility to metastasis $(P=0.0564 ; \mathrm{OR}=8.80 ; 95 \% \mathrm{CI}=1.29-60.13)$ and genotype -137GG presented marginal protection against secondary lesions $(P=0.0548 ; O R=0.14$; 
$95 \% \mathrm{CI}=0.02-1.21)$. Regarding genes $I F N-\gamma$ and $T N F-\alpha$, the allele and genotype frequencies did not differ significantly between the groups with and without metastasis.

The $14 \mathrm{bp} * \mathrm{D}$ allele in gene HLA-G was more frequent in cases of HCC compared to control, with the $14 \mathrm{bp}$ DD genotype tending to be more frequent among individuals with HCC. The alleles and genotypes of the $14 \mathrm{bp}$ insertion/deletion polymorphism of the $H L A-G$ were not associated with disease severity.

Chen et al., in a study of 150 individuals of the Chinese Han population, showed that genotypes of the $14 \mathrm{bp}$ insertion/deletion polymorphism of $H L A-G$ were significantly associated with the expression of soluble HLA-G in plasma in this population [35]. These authors detected a dramatically lower expression of soluble HLA-G in plasma in the presence of the $14 \mathrm{bp}$ I/I genotype than in the presence of the $14 \mathrm{bp} \mathrm{I} / \mathrm{D}(P=0.004)$ or $\mathrm{D} / \mathrm{D}(P=0.003)$ genotypes. No significant difference in plasma expression of soluble HLA-G was detected between $14 \mathrm{bp} \mathrm{I/D}$ and D/D genotypes.

Many mechanisms of tumor escape have been proposed in the literature, some of them local and others systemic. Particularly important among them is the expression of immunomodulatory molecules in the tumoral microbiota, as well as the expression of soluble suppressive factors by the tumoral cells. HLA-G represents one of these immunomodulatory molecules, playing an important role in the mechanisms of immunotolerance by the inhibition of the activity of NK cells, cytotoxic T lymphocytes and antigen-presenting cells [9,36].

The 14bp insertion/deletion polymorphism in exon 8 of HLA-G (3'UTR of the transcript) has been associated with the magnitude of protein production through the modulation of the stability of HLA-G mRNA, although the mechanisms involved still need to be elucidated. It has been demonstrated that the HLA-G allele containing the insertion polymorphism may suffer an additional splicing stage, so that $92 \mathrm{bp}$ are removed from the primary mRNA. Thus, smaller HLA-G transcripts, without the $92 \mathrm{bp}$, are more stable than the complete mRNA forms. The alternative splicing may also be related to the presence of other polymorphisms in linkage disequilibrium with the $14 \mathrm{bp}$ insertion $[8,10]$. Overall, HLA-G expression may be modulated by many actors including transcription factors (influenced by the $5^{\prime}$ polymorphisms of the promoter region) and the rate of mRNA degradation or translation, highly influenced by polymorphisms observed at 3'UTR [8]. Ferguson et al. recently reported that the risk for invasive cancer of the uterine cervix in a Canadian population was significantly higher in the presence of $14 \mathrm{bp}$ I/I genotype (OR=2.17, 95\% CI: 1.10-4.27, $\mathrm{P}=0.020)$ as well as homozygous genotypes HLA-G*01:01:02 (OR=3.52, 95\% CI: 1.43-8.61, $\mathrm{P}=0.006)$ and *01:06 (OR=19.1, 95\% CI: 2.29-159, $\mathrm{P}=0.005$ ) [12]. Similarly, Chen et al. studying the relationship between HLA-G gene polymorphism and the susceptibility of esophageal cancer in Kazakh and Han nationality in Xinjiang, found that the risk of developing esophageal cancer was significantly increased in individuals with $14 \mathrm{bp} \mathrm{I/I} \mathrm{genotype} \mathrm{compared} \mathrm{with} 14 \mathrm{bp}$ D/D genotype (OR=2.69, 95\% CI: 1.30-5.55, $\mathrm{P}=0.04$ ) in Kazakh population [11].

The tumoral microbiota or even the cells that underwent mutation per se can induce the expression of HLA-G. Studies have demonstrated the expression of HLA-G in various malignant tumors, although with variations in the percentage of lesions expressing the 
molecule. In studies involving renal cell carcinoma [37], endometrial adenocarcinoma [38] and gastric cancer [39], at least $30 \%$ of the tumors exhibited HLA-G expression.

Regarding hepatic diseases, Souto et al., in a study of 74 liver biopsies of individuals with chronic HBV infection and 10 specimens obtained from previously healthy cadaver liver donors, demonstrated that $77 \%$ of the samples of chronic HBV hepatitis presented HLA-G expression in the hepatocytes, as opposed to none of the controls [40]. These authors detected a case of HCC, in which HLA-G expression was not detected in the tumor cells but was detected in adjacent non-tumoral hepatic tissue.

Lin et al. evaluated by immunohistochemistry the expression of HLA-G in 219 HCC and adjacent nontumoral tissue samples. The expression of HLA-G was observed in $50.2 \%$ of HCC samples vs. $0 \%$ of normal corresponding adjacent tissue. Evaluation of HCC stages showed that HLA-G expression was detected in $37.8 \%, 41.9 \%$ and $71.4 \%$ of cases in stages I, II and III, respectively. The data reported by these authors revealed that the expression of HLA-G was strongly correlated with advanced HCC stage and that soluble HLA-G was significantly more elevated in the plasma of patients with HCC compared to healthy controls [41]. Similarly, Cai et al. studied the expression of HLA-G by immunohistochemistry in 173 HCC specimens and observed that HLA-G expression was associated with the prognosis of HCC, especially in the early stages of the disease, with higher HLA-G expression being independently associated with shorter overall survival and greater tumor recurrence after surgical resection [42].

Recently, a study involving 267 patients divided as anti-HBs positive healthy individuals $(n=50)$, chronic HBV carriers $(n=45)$, active hepatitis B $(n=46)$, liver cirrhosis $(n=46)$ and earlystage HCC patients $(n=80)$ showed that serum concentrations of soluble human leukocyte antigen-G (sHLA-G) were significantly higher in the active hepatitis B and HCC groups compared to the other groups $(\mathrm{P}<0.05)$. Moreover, the concentrations of sHLA-G were higher in the patients with HCC than in those with liver cirrhosis or active hepatitis B, suggesting that serum sHLA-G concentrations may be associated with the different phases of hepatitis B infection. They did not find any association between sHLA-G concentrations and HCC stage, number of tumors, pathologic grade and presence of vascular invasion [43]. Another study, examining fifteen SNPs in the non-classical class I alleles, found that the SNPs rs17875380, rs41557518, rs114465251, and rs115492845 were associated with susceptibility to chronic hepatitis B infection or HCC, and HLA-F*01:04, HLA-G*01:05N, and HLA-E*01:01 were associated with hepatitis B or hepatitis B with HCC, concluding that these polymorphisms may play an important role in immune surveillance of hepatitis B and HCC, possibly leading to immune responses to virus or cancer cells [14].

It has been demonstrated that, in addition to genetic factors, the microbiota, for example, strees inducers, hypoxia and cytokines (interferons, IL-10, TNF- $\alpha$ ), influences the expression of HLA$G$, so that more studies are needed for a better understanding of the interaction of molecules derived from the tumor and from host factors [9].

In summary, the present findings show that the deletion allele of the HLA-G 14bp insertion/ deletion polymorphism was more frequent among patients with tumors than among healthy individuals, a fact that may confer greater susceptibility to HCC. 
A higher frequency of the $I L-18-607^{*} \mathrm{~A}$ allele and -607AA genotype was found among HCC patients compared to healthy individuals in the present study. Mi et al. analyzed a pool of studies on the association between polymorphisms of the IL-18 gene and the risk of cancer (cancer of renal cells, of the ovary and breast, nasopharyngeal an cervical cancer, cancer of the esophagus, prostate, lung and stomach, and colorectal cancer) involving approximately 2137 cases and 3117 controls for the -607C/A variant, and 2372 cases and 3476 controls for the -137G/ $\mathrm{C}$ polymorphism, and they observed that the $-607^{*} \mathrm{~A}$ and $-137^{*} \mathrm{C}$ alleles were associated with an increased global risk of cancer compared to patients with the wild allele. Analysis of the different ethnic groups showed that these polymorphisms were associated with an increased risk of cancer in Asians but not in Europeans or Africans [44]. Regarding the evaluation of SNP $-137 \mathrm{C} / \mathrm{G}$, in the present study no significant differences in allele or genotype frequencies were detected between patients with HCC and healthy individuals. However, the IL18 -137G/-607A haplotype was more frequent among individuals with HCC than among control. These results suggest that, even though no association was detected between SNP -137G/C and HCC, the interaction between the two polymorphisms may have been involved in the susceptibility to HCC. Regarding the polymorphism of the IFN $-\gamma$ gene $(+874 \mathrm{~A} / \mathrm{T})$, no significant difference in allele or genotype frequencies were observed between patients with HCC and healthy controls. Migita et al. studied 236 Japanese patients with chronic HBV infection who were divided into two groups: with $(n=48)$ and without $(n=188)$ HCC, for the evaluation of the association of polymorphisms of the TNF- $\alpha, I F N-\gamma, T G F-\beta 1, I L-6$ and IL-10 genes with the risk of HCC. When evaluating the SNP +874 of IFN- $\gamma$, the authors did not detect a statistically significant difference between the two groups, as also observed in the present study [45].

We observed that alleles TNF- $\alpha-238^{*} \mathrm{~A}$ and $-308^{*} \mathrm{~A}$ confer significant susceptibility to HCC, and that genotypes TNF- $\alpha$-238GA and -308GA and haplotypes TNF- $\alpha-238 \mathrm{~A} /-308 \mathrm{G}$ and $-238 \mathrm{G} /-308 \mathrm{~A}$ are also more frequent among patients with HCC compared to control. Also in agreement with these results, Akkiz et al. when analyzing 110 patients with HCC and 110 healthy controls from the Turkish population, observed that patients with HCC had a higher frequency of genotype TNF- $\alpha$-308GA and a lower frequency of genotype TNF- $\alpha-308 \mathrm{GG}$ compared to control and after logistic regression, genotype -308GA was found to be associated with risk of HCC. In addition, individuals with the $-308^{*} \mathrm{~A}$ allele (genotypes -308AA and -308GA) had a 4.75-fold higher chance to develop HCC compared to individuals with the GG genotype [46]. Similarly, Jung et al., studying 227 Korean patients with HCC and 365 controls, detected a higher frequency of allele $-238^{*} \mathrm{~A}$ among patients with HCC than among healthy controls [47]. On the other hand, Yang et al., did not find statistical difference in TNF- $\alpha-308 \mathrm{G} /$ A alleles or genotypes frequencies between Chinese HCC patients $(n=772)$ and healthy controls $(\mathrm{n}=852)$, but they observed that TNF- $\alpha$-863AA genotype may increase the risk of HCC compared with the wild-type TNF- $\alpha$ CC [48].

The expression of TNF- $\alpha$ is regulated both at the transcriptional and post-transcriptional level and polymorphisms in the promoter region of TNF- $\alpha$ have been related to the production of this cytokine [22]. Greater TNF- $\alpha$ production up to five-fold the basal level and induction of mRNA expression have been associated with the TNF- $\alpha-308^{*} \mathrm{~A}$ allele, with elevated serum TNF levels being observed even in heterozygous patients [49]. Many mechanisms of the 
cancerigenous activity of TNF- $\alpha$ have been suggested, such as induction of pro-malignant chemokines, metalloproteinases, cell adhesion molecules, angiogenic mediators, reactive oxygen intermediates and inflammatory enzymes. Increased TNF- $\alpha$ levels are correlated with hepatic inflammation, fibrosis and tissue damage [46].

Studies evaluating the association of polymorphisms of $I L-18$ with the severity of cancer have been reported. Saenz-Lopez et al. investigated whether the presence of SNPs -137G/C and $-607 \mathrm{~A} / \mathrm{C}$ of $I L-18$ were associated with size, grade, and TNM Classification of 158 patients with renal cell carcinoma. These authors observed that genotype -607CC was significantly associated with larger tumor size $(P=0.001)$, grade $(P=0.030)$, and T $(P=0.001)$ and $\mathrm{M}(P=0.012)$ stage, while genotype -137GG was correlated with larger tumor size $(P=0.036)$, grade $(P=0.017)$, and stage T $(P=0.026)$ [50]. Another authors, studing the association of SNPs $-607 \mathrm{~A} / \mathrm{C}$ and $-137 \mathrm{G} / \mathrm{C}$ of $I L-18$ with histology of colorectal and gastric cancer (moderately differentiated or undifferentiated vs. well differentiated), noticed that no difference in genotype frequency was detected, although the combination of genotypes -607AA/-137GC was more frequent among patients with less differentiated tumors [51].

Literature evidence has demonstrated that IL-18 is a pleiotropic cytokine that enhances the Th1 or Th2 immune response according to the medium and to genetics. In the presence of IL-12, IL-18 induces IFN- $\gamma$ secretion by NK and T cells, activating the Th1 response, important for defense against tumor cells. On the other hand, IL-18 can increase tumor growth via increased stimulation of VEGF and of the immune response, and also stimulate solid tumor metastasis [52]. A possible explanation for this fact is the increased Th1 response in the early stages of the cancer which, however, is replaced with Th2 as tumor malignancy worsens with tumor development. Thus, as the tumor develops, $I L-18$ polymorphisms, which induce great IL-18 production, may contribute to the promotion of more advanced tumors due to the activation of angiogenesis, differentiation of tumor cells and regulation of stimulators of cell proliferation [53]. To corroborate these data, Tangkijvanich et al., in a study of 70 patients with HCC and 10 healthy controls, observed that serum IL-18 levels were significantly correlated with the presence of vascular invasion and of more advanced tumors according to the Okuda classification. In addition, the survival of patients with high serum levels of IL-18 was worse. Multivariate analysis showed that serum IL-18 levels proved to be a significant and independent prognostic factor regarding survival [54].

Regarding the $+874 \mathrm{~A} / \mathrm{T}$ polymorphism of the $I F N-\gamma$ gene, study involving 100 patients with chronic HCV infection and different degrees of disease severity (chronic hepatitis, $n=42$; cirrhosis + HCC, n=58) and 103 healthy controls detected that the TT and AT genotypes were significantly more frequent among patients with cirrhosis and HCC. These genotypes were associated with a 2.5 higher risk of progression to more severe forms of hepatic disease. In addition, the $+874^{*} \mathrm{~T}$ allele was approximately twice more frequent among patients in an advanced stage of hepatitis $C$ than among patients with chronic hepatitis, although multivariable analysis did not show that the $+874^{*} \mathrm{~T}$ allele was an independent predictive factor of severity [55]. 


\section{Conclusions}

Our results suggest that the $14 \mathrm{bp}$-deletion allele in $H L A-G$ gene is associated with HCC susceptibility in a Brazilian population, and that the alleles $I L-18-607^{*} \mathrm{~A}$ and TNF- $\alpha\left(-238^{*} \mathrm{~A}\right.$ and $-308^{*} \mathrm{~A}$ ) may confer susceptibility to HCC, whereas IL-18 $-607^{*} \mathrm{C}$ and $-137^{*} \mathrm{C}$ alleles may confer susceptibility to multinodular and diffuse HCC, respectively. Furthermore, deletion/ deletion genotype was marginally associated with greater risk of HCC. More studies in different populations are needed to confirm these findings.

\section{Author details}

Andreza Correa Teixeira ${ }^{1,2^{*}}$, Ana de Lourdes Candolo Martinelli ${ }^{1}$ and Eduardo Antonio Donadi ${ }^{1}$

*Address all correspondence to: andrezacteixeira@gmail.com

1 Department of Internal Medicine, Faculty of Medicine of Ribeirão Preto - University of São Paulo, Ribeirão Preto, São Paulo, Brazil

2 Department of Surgery and Anatomy, Faculty of Medicine of Ribeirão Preto - University of São Paulo, Ribeirão Preto, São Paulo, Brazil

\section{References}

[1] Bosch, F. X, Ribes, J, Díaz, M, \& Cléries, R. Primary liver cancer: worldwide incidence and trends. Gastroenterology (2004). Supplement 1.

[2] Jemal, A, Siegel, R, Ward, E, Hao, Y, Xu, J, \& Thun, M. J. Cancer statistics, 2009. CA: a cancer journal for clinicians (2009).

[3] Rockey, D. C, \& Friedman, S. L. Hepatic fibrosis and cirrhosis. In: Boyer TD, Wright TL, Manns MP. Hepatology. Philadelphia: Elselvier, (2006).

[4] Carrilho, F. J, Kikuchi, L, Branco, F, Goncalves, C. S, \& De Mattos, A. A. Brazilian HCC Study Group. Clinical and epidemiological aspects of hepatocellular carcinoma in Brazil. Clinics (2010). , 65(12), 1285-1290.

[5] Teixeira, A. C, \& Mente, E. D. Cantao CAB, Sankarankutty AK, Souza FF, Motta TC, Monsignore L, Elias-Junior J, Muglia VF, Abud DG, Peria FM, Zucoloto S, Castro-Silva O, Martinelli ALC Clinical Characteristics of 130 Patients With Hepatocellular Carcinoma Followed at a Tertiary Hospital From Brazil. World Journal of Oncology (2012). , 3(4), 165-172. 
[6] Abbas, A. K, Lichtman, A. H, \& Pillai, S. The major histocompatibility complex. In: . Cellular and Molecular Immunology. Philadelphia: Elsevier; (2007). , 97-112.

[7] Castelli, E. C, \& Mendes-junior, C. T. Deghaide NHS, de Albuquerque RS, Muniz YCN, Simoes RT, et al. The genetic structure of 3'untranslated region of the HLA-G gene: polymorphisms and haplotypes. Genes and Immunity (2010).

[8] Donadi, E. A, Castelli, E. C, Amaiz-villena, A, Roger, M, Rey, D, \& Moreau, P. Implications of the polymorphism of HLA-G on its function, regulation, evolution and disease association. Cellular and Molecular Life Sciences (2011).

[9] Carosella, E. D, \& Moreau, P. LeMaoult J, Rouas-Freiss N. HLA-G: from biology to clinical benefits. Trends in immunology (2008).

[10] Menier, C, Rouas-freiss, N, \& Favier, B. LeMaoult J, Moreau P, Carosella ED. Recent advances on the non-classical major histocompatibility complex class I HLA-G molecule. Tissue Antigens (2010).

[11] Chen, Y, Gao, X. J, Deng, Y. C, \& Zhang, H. X. Relationship between HLA-G gene polymorphism and the susceptibility of esophageal cancer in Kazakh and Han nationality in Xinjiang. Biomarkers (2012).

[12] Ferguson, R, Ramanakumar, A. V, Koushik, A, Coutlée, F, \& Franco, E. Roger M; Biomarkers of Cervical Cancer Risk Study Team. Human leukocyte antigen G polymorphism is associated with an increased risk of invasive cancer of the uterine cervix. International Journal of Cancer (2012). E, 312-9.

[13] Jiang, Y, Chen, S, Jia, S, Zhu, Z, Gao, X, Dong, D, \& Gao, Y. Association of HLA-G 3' UTR bp insertion/deletion polymorphism with hepatocellular carcinoma susceptibility in a Chinese population. DNA Cell Biology (2011). , 14.

[14] Zhang, J, Pan, L, Chen, L, Feng, X, Zhou, L, \& Zheng, S. Non-classical MHC-I genes in chronic hepatitis B and hepatocellular carcinoma. Immunogenetics (2012).

[15] Budhu, a. Wang xw. The role of cytokines in hepatocellular carcinoma. J Leukoc Biol (2006). , 80, 1197-213.

[16] Bidwell, J, Keen, L, Gallagher, G, Kimberly, R, Huizinga, T, Mcdermott, M. F, Oksenberg, J, Mcnicholl, J, Pociot, F, Hardt, C, \& Alfonso, D. S. Cytokine gene polymorphism in human disease: on-line databases. Genes Immun (2001). , 2, 61-70.

[17] Bayley, J. P, Ottenhoff, T. H, \& Verweij, C. L. Is there a future for TNF promoter polymorphisms? Genes Immun (2004). , 5, 315-29.

[18] Teixeira, A. C, Mendes-júnior, C. T, \& Souza, F. F. Cantão CAB, Ferreira SC, Deghaide NHS, Castelli EC, Mente ED, Sankarankutty AK, Zucoloto S, Elias Jr J, Muglia V, Castro-Silva O, Donadi EA, Martinelli AC. Alleles and Genotypes of IL-18 and TNF- $\alpha$ Promoter Polymorphisms are Associated with Higher Risk of Hepatocellular Carcinoma (HCC) in Brazilian Population. J Hepatol. (2010). Suppl1): S236. 
[19] Teixeira, A. C, Castelli, E, Souza, F, Cantão, C, Ferreira, S, Mendes-júnior, C, Deghaide, N, Mente, E, Sankarankutty, A, Zucoloto, S, Ramalho, L, Crispim, J, Castro-esilva, O, \& Donadi, E. Martinelli ALC. The 14BP-Deletion Polymorphism in HLA-G Gene Confers Susceptibility to the Development of Hepatocellular Carcinoma (HCC) in Brazilian Population. J Hepatol. (2010). Suppl1): S236.

[20] Teixeira, A. C, Mendes-junior, C. T, Souza, F. F, \& Marano, L. A. Deghaide NHS, Ferreira SC, Mente ED, Sankarankutty AK, Elias-Junior J, Castro-Silva O, Donadi EA, Martinelli ALC. The 14bp-deletion allele in the HLA-G gene confers susceptibility to the development of hepatocellular carcinoma (HCC) in the Brazilian population. Tissue Antigens. 2013 Mar 18. doi: 10.1111/tan.12097. [Epub ahead of print]

[21] Teixeira, A. C, Mendes-junior, C. T, \& Marano, L. A. Deghaide NHS, Secaf M, EliasJunior J, Muglia V, Donadi EA, Martinelli ALC. Alleles and genotypes of polymorphisms of IL-18, TNF- $\alpha$ and IFN- $\gamma$ are associated with a higher risk and severity of hepatocellular carcinoma (HCC) in Brazil Human Immunology (accepted for publication).

[22] Bruix, J, Sherman, M, Llovet, J. M, Beaugrand, M, Lencioni, R, Burroughs, A. K, et al. Clinical Management of Hepatocellular Carcinoma. Conclusions of the Barcelona-2000 EASL Conference. Journal of hepatology (2001).

[23] Bruix, J, \& Sherman, M. AASLD Practice Guideline. Management of hepatocellular carcinoma. Hepatology (2005).

[24] Edmondson, H. A, \& Steiner, P. E. Primary carcinoma of the liver: a study of 100 cases among 48900 necropsies. Cancer (1954).

[25] Miller, A. S. A simple salting out procedure for extracting DNA for human nucleated cells. Nucleic acids research (1988).

[26] Bermingham, J, Jenkins, D, Mccarthy, T, \& Brien, O. M. Genetic analysis of insulinlike growth factor II and HLA-G in pre-eclampsia. Biochemical Society Transactions. (2000).

[27] Castelli, E. C, \& Mendes-junior, C. T. Viana de Camargo JL, Donadi EA. HLA-G polymorphism and transitional cell carcinoma of the bladder in a Brazilian population. Tissue antigens (2008).

[28] MarshHP; Haldar, NA; Bunce, M; Marshall, SE; le Monier, K; Winsey, SL; Christodoulos, K; Cranston, D; Welsh, KI; Harris, AL. Polymorphisms in tumour necrosis factor (TNF) are associated with risk of bladder cancer and grade of tumour at presentation. Br J Cancer (2003). , 89(6), 1096-101.

[29] PravicaV; Perrey, C; Stevens, A; Lee, J-H; Hutchinson, IV. A single nucleotide polymorphism in the first intron of the human IFN-gamma gene: absolute correlation with a polymorphic CA microsatellite marker of high IFN-gamma production. Human Immunol (2000). , 61(9), 863-66. 
[30] Guo, S. W, \& Thompson, E. A. Performing the exact test of Hardy-Weinberg proportion for multiple alleles. Biometrics (1992).

[31] ExcoffierL; Laval, G; Schneider, S. Arlequin ver. 3.0: an integrated software package for population genetics data analysis. Evolutionary bioinformatics online (2005). , 1, 47-50.

[32] Stephens, M, Smith, N. J, \& Donnelly, P. A new statistical method for haplotype reconstruction from population data. American journal human genetics (2001). , 68(4), 978-89.

[33] Excoffier, L, \& Slatkin, M. Maximum-likelihood estimation of molecular haplotype frequencies in a diploid population. Mol Biol Evol (1995). , 12, 921-927.

[34] Mazzaferro, V, Regalia, E, Doci, R, Andreola, S, Pulvirenti, A, Bozzetti, F, Montalto, F, Ammatuna, M, Morabito, A, \& Gennari, L. Liver Transplantation for the Treatment of Small Hepatocellular Carcinomas in Patients with Cirrhosis. N Engl J Med (1996). , 334, 693-700.

[35] Chen, X. Y, Yan, W. H, Lin, A, Xu, H. H, Zhang, J. G, \& Wang, X. X. The 14 bp deletion polymorphisms in HLA-G gene play an important role in the expression of soluble HLA-G in plasma. Tissue antigens (2008).

[36] Yie, S. M, \& Hu, Z. Human Leukocyte Antigen-G (HLA-G) as a marker for diagnosis, prognosis and tumor immune escape in human malignancies. Histology and histopathology (2011).

[37] Seliger, B, \& Schlaf, G. Structure, expression and function of HLA-G in renal cell carcinoma. Seminars in cancer biology (2007).

[38] Barrier, B. F, Kendall, B. S, Sharpe-timms, K. L, \& Kost, E. R. Characterization of human leukocyte antigen-G (HLA-G) expression in endometrial adenocarcinoma. Gynecologic oncology (2006).

[39] Yie, S. M, Yang, H, Ye, S. R, Li, K, Dong, D. D, \& Lin, X. M. Expression of human leukocyte antigen G (HLA-G) correlates with poor prognosis in gastric carcinoma. Annals of surgical oncology (2007).

[40] Souto, F. J, Crispim, J. C, \& Ferreira, S. C. da Silva AS, Bassi CL, Soares CP, et al. Liver HLA-G expression is associated with multiple clinical and histopathological forms of chronic hepatitis B virus infection. Journal of viral hepatitis (2011).

[41] Lin, A, Chen, H. X, Zhu, C. C, Zhang, X, Xu, H. H, Zhang, J. G, et al. Aberrant human leucocyte antigen-G expression and its clinical relevance in hepatocellular carcinoma. Journal of cellular and molecular medicine (2010).

[42] Cai, M. Y, Xu, Y. F, Qiu, S. J, Ju, M. J, Gao, Q, Li, Y. W, et al. Human leukocyte antigen-G protein expression is an unfavorable prognostic predictor of hepatocellular carcinoma following curative resection. Clinical cancer research (2009). 
[43] Park, Y, Park, Y, Lim, H. S, Kim, Y. S, Hong, D. J, \& Kim, H. S. Soluble human leukocyte antigen-G expression in hepatitis B virus infection and hepatocellular carcinoma.Tissue Antigens (2012).

[44] Mi, Y. Y, Yu, Q. Q, Yu, M. L, Xu, B, Zhang, L. F, Cheng, W, Zhang, W, Hua, L. X, \& Feng, N. H. Review and pooled analysis of studies on-607(C/A) and-137(G/C) polymorphisms in IL-18 and cancer risk. Med Oncol. (2011). , 28(4), 1107-15.

[45] Migita, K, Miyazoe, S, Maeda, Y, Daikoku, M, Abiru, S, Ueki, T, Yano, K, Nagaoka, S, Matsumoto, T, Nakao, K, Hamasaki, K, Yatsuhashi, H, Ishibashi, H, \& Eguchi, K. Cytokine gene polymorphisms in Japanese patients with hepatitis B virus infection--association between TGF-beta1 polymorphisms and hepatocellular carcinoma. J Hepatol (2005). , 42, 505-10.

[46] Akkiz, H, Bayram, S, Bekar, A, Ozdil, B, Akgöllü, E, Sümbül, A. T, Demiryürek, H, Doran, F. G, \& Tnf-alpha, A. polymorphism is associated with an increased risk of hepatocellular carcinoma in the Turkish population: case-control study. Cancer Epidemiol (2009). , 33, 261-4.

[47] Jung, K. W, Ha, E, Yu, G. I, Kim, S. J, Chung, W. J, Jang, B. K, Lee, J. J, Shin, D. H, \& Hwang, J. S. TNFalpha promoter polymorphism is a risk factor for susceptibility in hepatocellular carcinoma in Korean population. Clin Chim Acta (2009). , 407, 16-9.

[48] Yang, Y, Qiu, X. Q, Yu, H. P, Zeng, X. Y, \& Bei, C. H. TNF- $\alpha-863$ polymorphisms and the risk of hepatocellular carcinoma. Exp Ther Med. (2012). , 3(3), 513-518.

[49] Abraham, L. J, \& Kroeger, K. M. Impact of the-308 TNF promoter polymorphism on the transcriptional regulation of the TNF gene: relevance to disease. J Leukoc Biol (1999). , 66, 562-6.

[50] Sáenz-lópez, P, Carretero, R, Vazquez, F, Martin, J, Sánchez, E, Tallada, M, Garrido, F, Cózar, J. M, \& Ruiz-cabello, F. Impact of interleukin-18 polymorphisms-607 and-137 on clinical characteristics of renal cell carcinoma patients. Human Immunol (2010). , 309-313.

[51] Haghshenas, M. R, Hosseini, S. V, Mahmoudi, M, Saberi-firozi, M, Farjadian, S, Ghaderi, A, \& Serum, I. L. level and IL-18 promoter gene polymorphism in Iranian patients with gastrointestinal cancers. J Gastroenterol Hepatol (2009). , 26(6), 1119-22.

[52] Nakanishi, K, Yoshimoto, T, Tsutsui, H, \& Okamura, H. Interleukin-18 is a unique cytokine that stimulates both Th1 and Th2 responses depending on its cytokine milieu. Cytokine Growth Factor Rev (2001). , 12(1), 53-72.

[53] Mojtahedi, Z, \& Interleukin, I. L. may enhance Th1 response in early cancer but aggravate malignant disease in its later stages. Med Hypotheses (2005). , 65(5), 995-6.

[54] Tangkijvanich P; Thong-NgamD.; Machachai, V.; Theamboonlers, A.; Poovorawan, Y. Role of serum interleukin-18 as a prognostic factor in patients with hepatocellular carcinoma. World J Gastroenterol (2007). , 13(32), 4345-9. 
[55] Bouzgarrou, N, Hassen, E, Farhat, K, Bahri, O, Gabbouj, S, \& Maamouri, N. Ben Mami, N.; Saffar, H.; Trabelsi, A.; Triki, H.; Chouchane, L. Combined analysis of interferon-gamma and interleukin-10 gene polymorphisms and chronic hepatitis $\mathrm{C}$ severity. Human Immunol (2009). , 70(4), 230-6. 